Article

\title{
Supervisory Power Coordination Scheme to Mitigate Power Curtailment in the Application of a Microgrid
}

\author{
Heesang Ko*D, Gihoon Kim $\mathbb{D}$, Yanghyun Nam and Kyungsang Ryu \\ Power System Research Team, Korea Institute of Energy Research, Jeju-si 63357, Korea; ghk@kier.re.kr (G.K.); \\ yh_nam@kier.re.kr (Y.N.); ksryu@kier.re.kr (K.R.) \\ * Correspondence: heesangko@kier.re.kr
}

Citation: Ko, H.; Kim, G.; Nam, Y.; Ryu, K. Supervisory Power Coordination Scheme to Mitigate Power Curtailment in the Application of a Microgrid. Processes 2021, 9, 1998. https://doi.org/10.3390/pr9111998

Academic Editor: Chunsing Lai

Received: 25 September 2021

Accepted: 4 November 2021

Published: 9 November 2021

Publisher's Note: MDPI stays neutral with regard to jurisdictional claims in published maps and institutional affiliations.

Copyright: (c) 2021 by the authors. Licensee MDPI, Basel, Switzerland. This article is an open access article distributed under the terms and conditions of the Creative Commons Attribution (CC BY) license (https:// creativecommons.org/licenses/by/ $4.0 /)$.

\begin{abstract}
There are cases where the output of renewable eappennergy (RE) is curtailed due to an increase in the share of RE. Typically, wind power (WP) is curtailed due to oversupply and low loads at midnight. However, there are cases where the output of WP is limited during the daytime due to the increase in the share of photovoltaics (PV). In the current electricity market, as the share of $\mathrm{PV}$ is increased, the curtailments of WP will be increased further, which will add to the difficulties experienced by wind farm operators. This paper proposes a supervisory power coordination scheme. The main purposes are to prevent the penetration of extra power from REs into the grid; thus, the curtailments can be prevented. In order to make it feasible, the proposed scheme is to design a gridconnected microgrid system to be operated only in response to loads and virtual power plant (VPP) requests. The effectiveness of the proposed scheme was verified by simulation studies conducted in the MATLAB/Simulink environment. The verification was conducted based on the voltage criteria, such as the $\mathrm{AC}$ voltage regulation between $\pm 6 \%$ of the rated $\mathrm{AC}$ voltage, the $\mathrm{DC}$ voltage regulation between $\pm 10 \%$ of the rated DC voltage, the power balance according to variations in the loads, and VPP requests for power. The simulation showed that the proposed scheme is feasible and justifiable, not only to mitigate the power curtailment problem but also to apply different system configurations.
\end{abstract}

Keywords: power coordination; power curtailment; VPP; microgrid; energy storage system; photovoltaic system; interlinking converter; DC/DC converter

\section{Introduction}

Due to the binary nature of electricity, microgrids are broadly classified as AC and DC microgrids. However, to comply with the AC system and to interface with the growing DC technologies, coupled AC and DC grids, or AC/DC hybrid microgrid structures, are currently receiving significant attention. The advantage of this structure is that it can accommodate both AC and DC loads and generators instantaneously with minimum $\mathrm{AC} / \mathrm{DC} / \mathrm{AC}$ power conversion. In addition, this structure is suitable for integrating distributed storage such as in the emerging electric vehicle energy storage systems (EV-ESS) for vehicle-to-grid (V2G) applications [1].

High-voltage direct current has been used to connect large-scale grid connections between countries and to incorporate large wind farms into transmission systems. In medium- or low-voltage systems, due to an increase in DC loads and inverter-interfaced distribution generation, DC grids are constructed by converting the AC operations to DC. This can cause electricity losses as well as incurring the initial capital costs associated with voltage-sourced converters (VSCs), but it can control the line power flow and increase the power capability [2]. In addition, the DC power grid can be more efficient in integrating renewable energy sources [3,4]. The development of DC grids has led to AC/DC hybrid microgrids. The advantage of an AC/DC hybrid microgrid is that it reduces the number of energy conversion stages and combines the benefits of AC and DC systems [5].

A microgrid refers to a small-scale distribution network designed to actively manage the power and energy locally, which is essentially an active distribution system [2]. The 
concept of the AC/DC hybrid microgrid is the same as a conventional pure AC microgrid, but with the addition of a DC grid. A static switch is placed at the point of common coupling or point of interconnection, and there are various energy resources and some controllable loads in AC/DC hybrid microgrids. Typically, but not necessarily, AC loads are in the AC grid and DC loads are in the DC grid. The purpose of such a configuration is to improve energy efficiency. The energy resources are also placed similarly.

Unlike the typical structure in which the main grid is connected to the AC grid, in the AC/DC hybrid microgrid structure, the DC grid is linked to the main grid through the power conversion devices, and static switch is possible [6]. In this structure, the frequency of the AC grid can differ from the main grid due to two voltage conversions (between the DC grid and the main grid, and the DC grid and the AC grid). This structure is more typical at the medium or high voltage level to interconnect with other regions.

One major issue with the current power system is the introduction of DC technology into the system. Initially, DC devices were connected to the AC grid via inverters, but as the number of DC devices increases and the awareness of energy efficiency rises, more DC grids in which the energy is transmitted through the DC line are now being constructed. In the DC grid, there is no system frequency or reactive power flow. Frequency acts as a global variable, and it can be used to recognize the generation and load mismatch in the AC power grid. However, in the DC power grid, the DC voltage is used in a similar way, but it may not provide accurate information because the voltage magnitude is different in the buses due to line resistance. In addition, the voltage should be regulated by the active power.

As typical control schemes, hierarchical microgrid controls have been researched substantially [7-19]. However, it is shown that such an autonomous control scheme fails to function due to variations such as droop coefficients and the loss/connection of renewable energy sources.

Power curtailment issues have recently arisen due to the high penetration of REs into grids. Approximately 6.5 million MWh of PV output was curtailed in Chile, China, Germany, and the United States [20]. It is difficult for grid operators to manage a great number of distributed energy resources (DERs) without visibility.

In the United States, a network operation center (NOC)-type load management business model that remotely controls demand response resources using a communication network is active, centering on private companies such as EnerNOC and Comverge.

Portland General Electric (PGE) is developing its own self-contained $45 \mathrm{MW}$ generator composed of 32 generators in 21 consumer districts in Oregon through a Dispatchable Standby Generation (DSG) program that integrates consumer-owned emergency generators rather than demand response and uses them to reduce peak loads.

The driving force behind VPP development in the EU is the expansion of RE and distributed generation (DG) distributions and energy efficiency improvements for reducing greenhouse gas emissions and relieving dependence on fossil fuels. In other words, in order to actively respond to problems related to stability and power quality in the distribution network that may occur due to the expansion of RE and DG distributions, and to allow small DERs to participate in the power market, this dispersion is used to improve the overall system operation efficiency. A technology platform for the integrated operation and control of these types of resources is the core of the VPP concept in the EU.

In Jeju, Korea, the number of curtailments increased from 7 in the year 2018 to 77 in the year 2020, which is related to a waste of energy totaling 19,449 MWh. The expected number of power curtailments in the year 2021 is 240, meaning that 60,000 MWh of energy will be wasted. Thus, Korea has recently urged the mitigation of power curtailments utilizing ESSs, as well as technical innovation of the photovoltaic system.

This paper proposes a supervisory power coordination scheme to prevent excessive power generation from REs. The key technology is a scheme that corresponds only to load variations and VPP requests. 
The organization of this paper is as follows: system descriptions are provided in Section 2, the power coordination methodology is presented in Section 3, the case studies using simulations are described in Section 4, and the conclusion is provided in Section 5.

\section{System Descriptions}

A. System Configuration

Figure 1 indicates the proposed system configuration. All AC and DC components are interlinked at the DC common bus. The AC subgrid is represented by the AC constant voltage source, the AC load, and the VPP's request and is linked to the DC common bus through the AC/DC interlinking converter (IC) with the LCL filter. The DC subgrid consists of an ESS and a PV and is connected to the DC common bus through its own DC/DC converter. The AC load is modeled as single-phase resistance, and its voltage is assumed to be AC $220 \mathrm{~V}$. The VPP's request is assumed to be $\mathrm{kW}$ time step variations in the active power. The ESS is expressed by the battery and the bidirectional DC/DC converter with the associated controller, and its capacity is assumed to be $15 \mathrm{kWh}$. Finally, the PV is modeled by the PV arrays and the boost DC/DC converter with its associated MPPT control, and its capacity is considered to be $11 \mathrm{~kW}$.

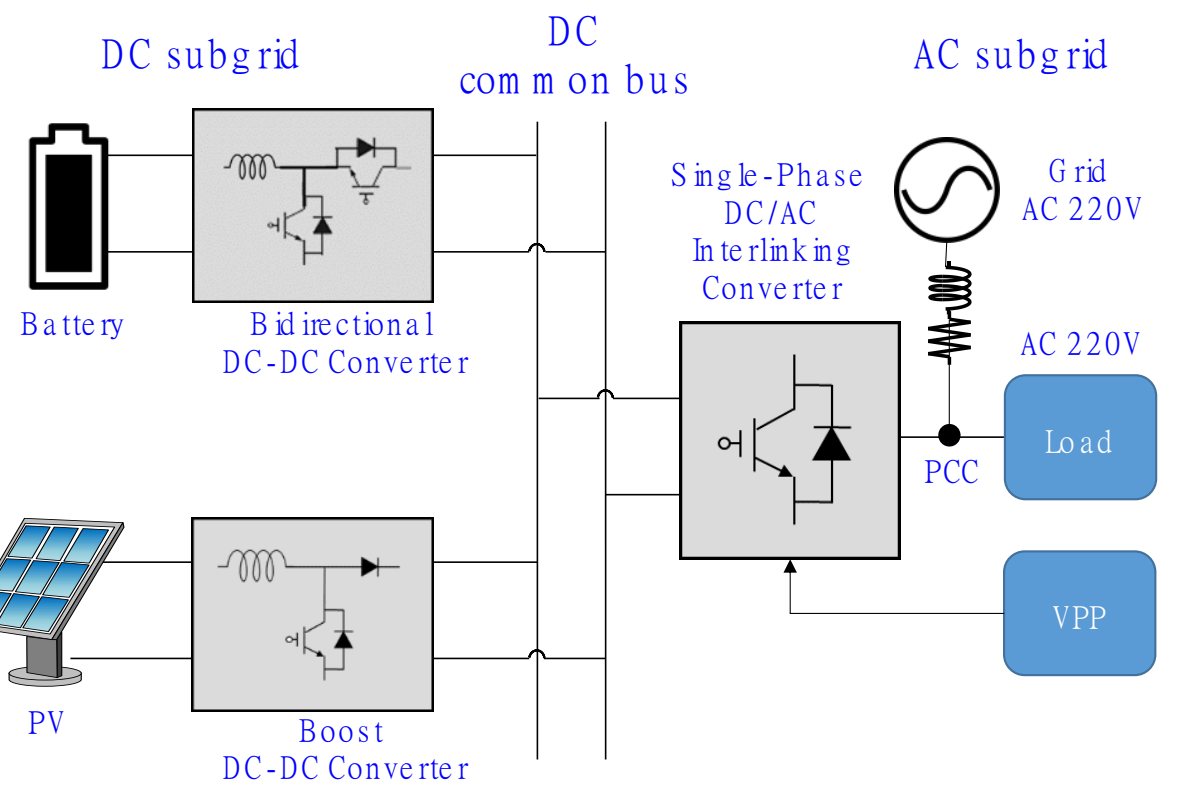

Figure 1. The architecture of the proposed AC/DC-interlinked hybrid microgrid.

The overall system model is simulated at the sampling time of $10 \times 10^{-6} \mathrm{~s}$. In order to realize a real-time simulation, the sampling time of the controller is set to $10 \times 10^{-4} \mathrm{~s}$ to take into account the communication delays. The switching frequency of all converters is assumed to be $20 \mathrm{kHz}$. Detailed information about the dynamic simulation parameters and sub-models can be found in Appendices A and B, respectively.

B. Point of Common Coupling (PCC)

The PCC is located between the AC load and the AC/DC interlinking converter (IC), as shown in Figure 1.

\section{AC/DC Interlinking Converter (IC)}

Switch 1 in the AC/DC interlinking converter plays an important role according to the state of charge (SOC) of the battery. According to the SOC and the VPP's request, switch 1 's operations can be briefly summarized as follows: 
(1) If $S O C(t)<30 \%$ : the ESS charges until the SOC reaches its pre-defined value (e.g., $50 \%$ in this paper), and the DC link voltage is controlled by the IC.

(2) If $\operatorname{SOC}(t)>30 \%$ : the DC link voltage is controlled by the ESS, and the constant voltage-constant frequency (CVCF) is controlled by the IC.

(3) If VPP's request: the DC link voltage is controlled by the ESS, and the active power is controlled by the IC.

The pre-defined value of the SOC is changeable with respect to the system operating conditions.

As illustrated in Figure 2, the IC controller consists of a second-order generalized integrator (SOGI)-based phase-locked loop (PLL), a proportional-integral (PI)-based current and voltage controller, etc. The parameters are presented in Appendix A. Dynamic models for the rest of the blocks such as SVPWM, Park Transformation, and All Pass Filter can be found in [21].

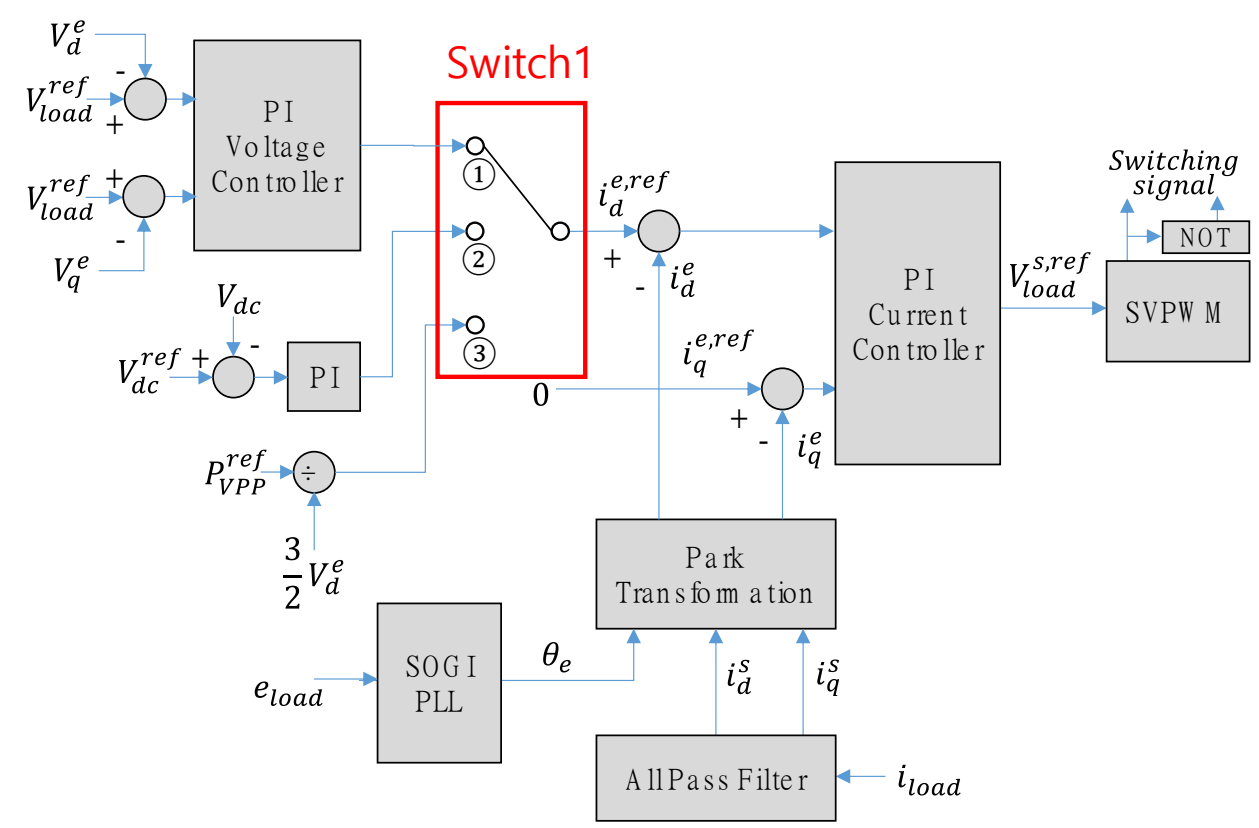

Figure 2. Control block diagram of the AC/DC interlinking converter (IC).

D. Energy Storage System (ESS)

The modeling is carried out based on concepts presented in [22]. Here, the ESS is modeled by the battery, the bidirectional DC/DC converter, and the associated controls in order to perform the discharging and charging operations [23]. The parameters of the PIs are presented in Appendix A.

Figure 3 presents the control block diagram of the bidirectional DC/DC converter. Switch 2 's operations can be summarized as follows:

(1) If $30 \% \leq S O C(t) \leq 90 \%$ : the DC link voltage is controlled by the ESS, PV MPPT ON, and the CVCF is controlled by the IC, Grid OFF.

(2) If $S O C(t)<30 \%$ : PV MPPT ON, the DC link voltage is controlled by the IC, and the active power is controlled by the ESS until the SOC reaches its pre-defined value.

(3) If $\operatorname{SOC}(t)<30 \%$ : this defines the emergency situation; thus, the ESS is set to STOP. 


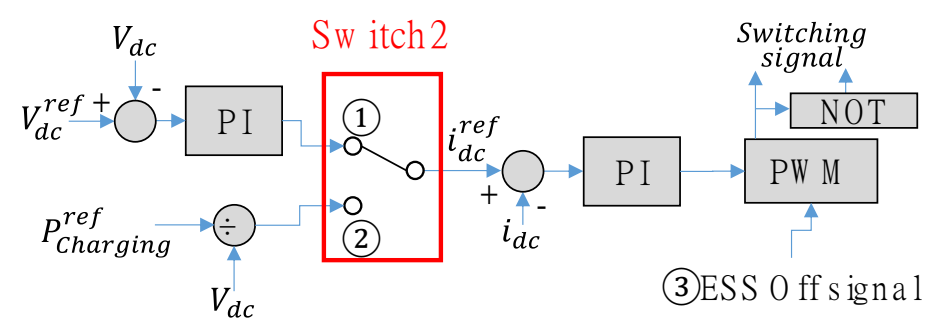

Figure 3. Control block diagram of the bidirectional DC/DC converter of the ESS.

E. Photovoltaic System (PV)

The PV consists of models of the PV arrays, the DC/DC converter, and the associated control MPPT. The equivalent circuit used in the model is the one-diode model with shunt and series resistance. More detailed information can be found in [22].

Switch $3^{\prime}$ s operations in Figure 4 can be simply described as follows:

(1) If $30 \% \leq S O C(t) \leq 90 \%$ : PV MPPT ON, the DC link voltage is controlled by the ESS; Grid OFF, the CVCF is controlled by the IC.

(2) If $S O C(t)>90 \%$ : PV OFF, the ESS discharges until the SOC reaches the pre-defined value; Grid OFF, the CVCF is controlled by the IC.

(3) If $S O C(t)<30 \%$ : PV OFF, the ESS charges until the SOC reaches the pre-defined value, and the DC link voltage is controlled by the IC, Grid ON.

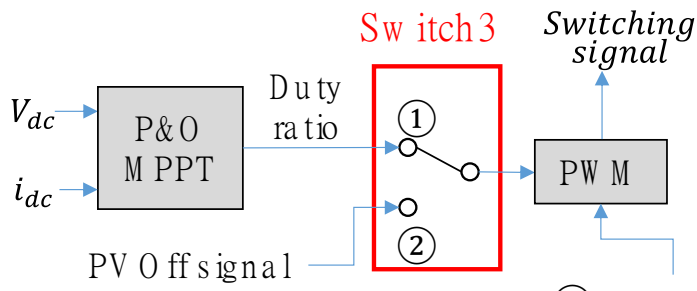

(3)PV 0 ff signal

Figure 4. Control block diagram of the boost DC/DC converter of the PV.

\section{F. Virtual Power Plant (VPP)}

The VPP's request is represented by the $\mathrm{kW}$ time step variation. Such a representation takes into account the power trade between the DC subgrid with the load and the VPP, as shown in Figure 1. In this paper, a positive VPP request is considered to be when the power flow is from the AC grid to the DC subgrid and the load. A negative VPP request is considered to be when the power flows from the DC subgrid with the load to the AC grid. There may not be sufficient power reservoirs in the DC subgrid in order to fully respond to the VPP's request $P_{V P P}^{\text {request }}$. Thus, the final VPP request $P_{V P P}^{r e f}$ described in Figure 2 is limited by taking into account the battery SOC or the battery voltage $V_{\text {battery }}$, as defined in Equations (1) and (2), respectively. In this paper, Equation (1) was adapted due to its conventional use in industry applications.

$$
\begin{gathered}
-\left(\frac{S O C_{\text {measured }}(t)}{S O C_{100 \%}}\right) \times P_{V P P}^{\text {request }}(t) \leq P_{V P P}^{\text {ref }}(t) \leq+\left(\frac{S O C_{\text {measured }}(t)}{S O C_{100 \%}}\right) \times P_{V P P}^{\text {request }}(t) \\
-\left(\frac{V_{\text {battery }}(t)}{V_{\text {battery }}^{\text {rated }}}\right) \times P_{V P P}^{\text {request }}(t) \leq P_{V P P}^{\text {ref }}(t) \leq+\left(\frac{V_{\text {battery }}(t)}{V_{\text {battery }}^{\text {rated }}}\right) \times P_{V P P}^{\text {request }}(t)
\end{gathered}
$$

\section{Supervisory Power Coordination Scheme}

This section presents the supervisory power coordination scheme. The overall objective is to distribute the power required by the loads and VPPs by taking into account 
the operating conditions of the REs. This, in turn, means that the power supply to the load only comes from the REs. The power exchange between the REs and the grid only occurs when there is a request from the VPP so that there is no extra power penetration into the grid. As a result, any power curtailment of REs connected to the grid can be prevented; subsequently, the sale and purchase of power can be performed only when required, without harming the stability of the system. Figure 5 shows a visual comparison between conventional operations and the proposed operations.

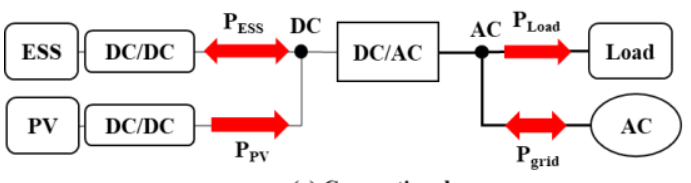

(a) Conventional

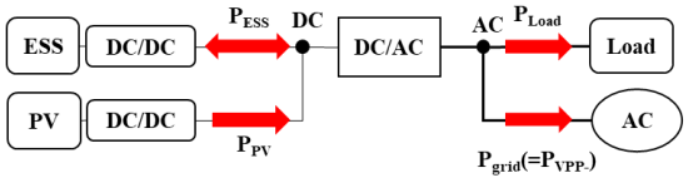

(c) $\operatorname{VPP}(\mathrm{ON})$

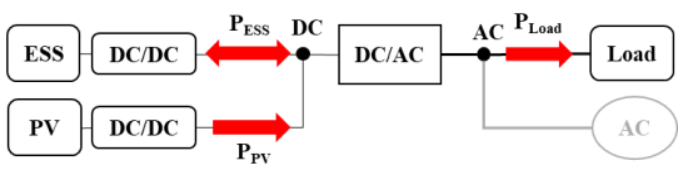

(b) $\operatorname{VPP}(\mathrm{OFF})$

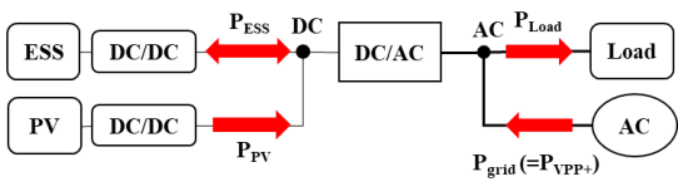

(d) $\operatorname{VPP}(\mathrm{ON})$

Figure 5. Comparison between the conventional and proposed operations.

In Section 2, the switch operations of the proposed control schemes were briefly introduced. In this section, the proposed operation process is described based on Figure 6.

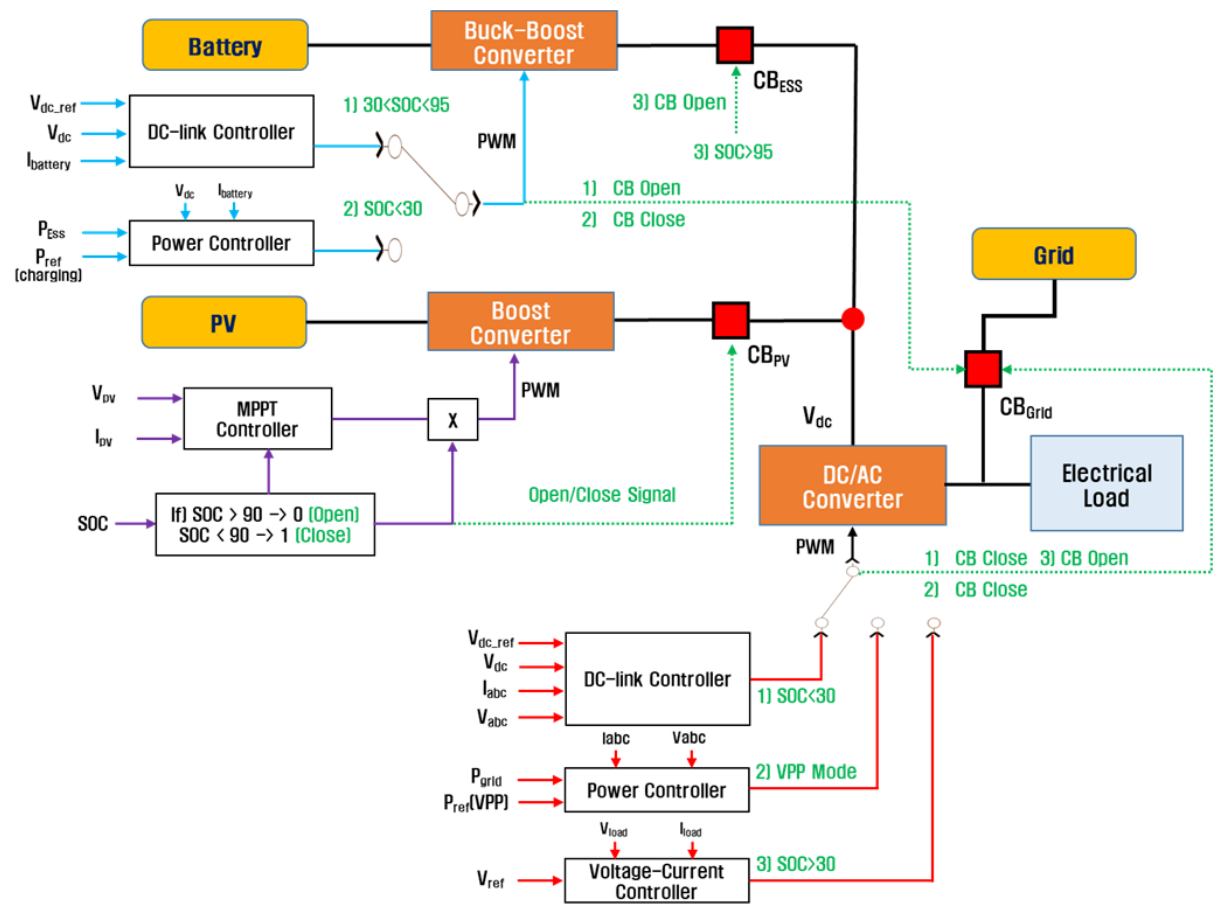

Figure 6. The overall implementation block diagram for the proposed scheme.

Figures 7 and 8 are representations of Figure 6. Figure 7 is the case when there is a VPP request. Figure 8 is the case when there is no VPP request. The pre-defined SOC parameters shown in Figures 7 and 8 were used for the simulation studies. The VPP's request means there is a power trade between the AC grid and the DC subgrid with the loads. Moreover, the pre-defined SOC value can be changed according to the system characteristics and overall system operating conditions. 


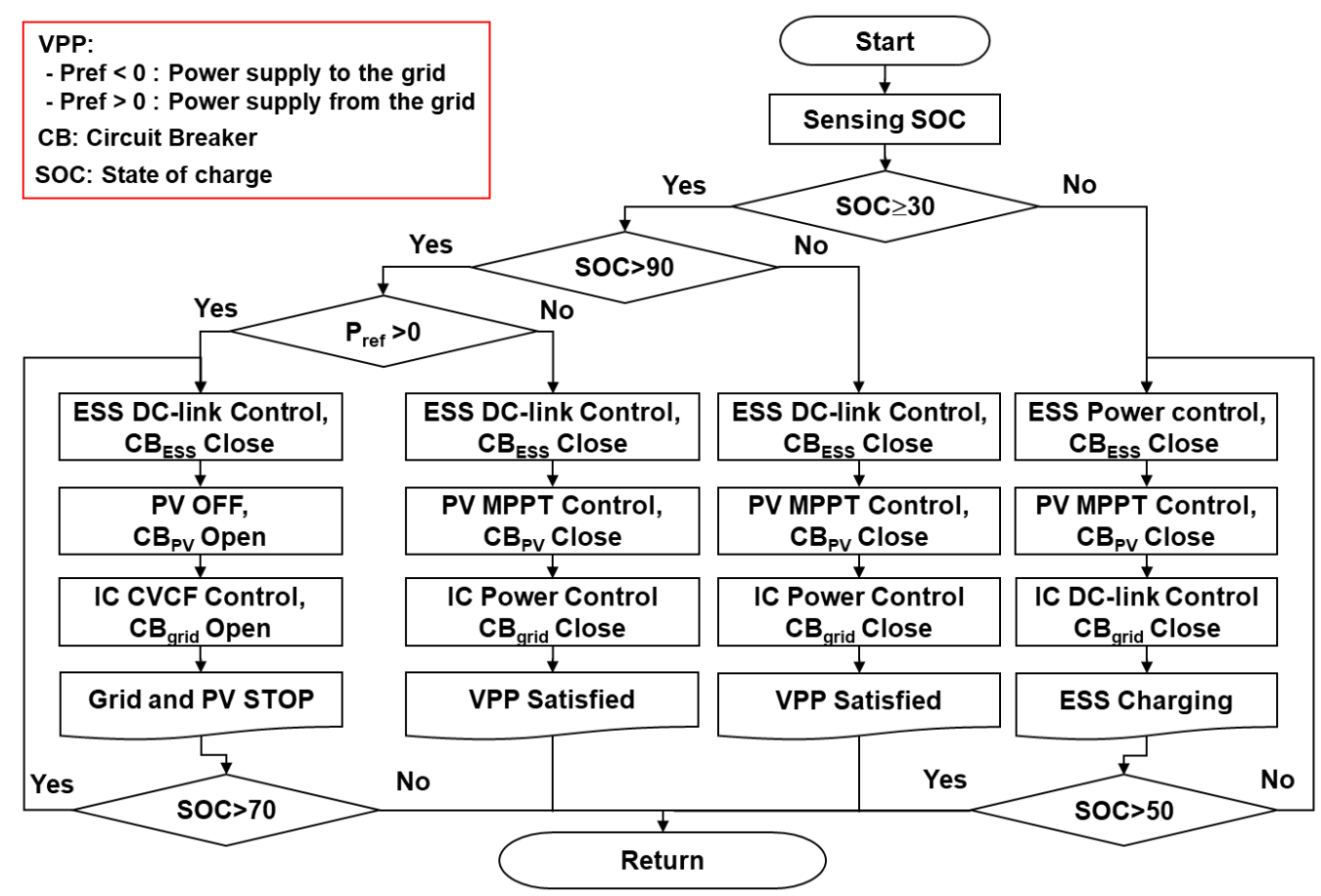

Figure 7. The proposed supervisory power coordination scheme with a VPP request.

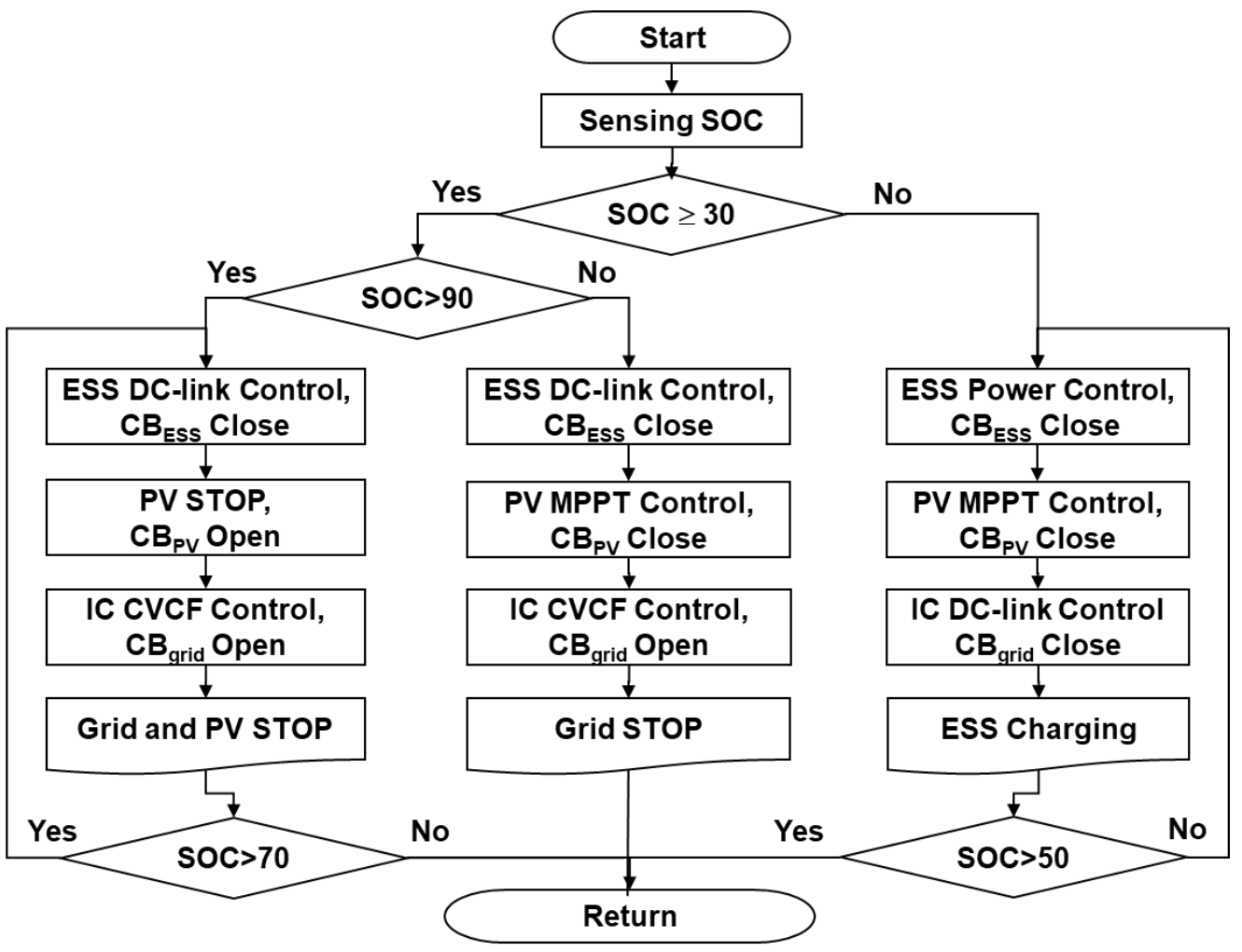

Figure 8. The proposed supervisory power coordination scheme without a VPP request.

\section{Case Studies}

The simulation studies were conducted in the MATLAB/Simulink environment [24]. The simulation models are presented in Appendix B. The simulation conditions are summarized as follows (Table 1): 
Table 1. System Parameters.

\begin{tabular}{ll}
\hline \multicolumn{1}{c}{ Items } & \multicolumn{1}{c}{ Parameters } \\
\hline Grid voltage & AC 220 V \\
Single-phase PCC voltage & AC 220 V \\
PCC voltage & AC 220 V \\
DC link voltage & DC $1000 \mathrm{~V}$ \\
ESS capacity & $15 \mathrm{kWh}$ \\
PV capacity & $11 \mathrm{~kW}$ \\
Initial SOC & $50 \%$ \\
Rated battery voltage & $\mathrm{DC} 350 \mathrm{~V}$ \\
AC load time step variation & $1 \mathrm{~s}, 2 \mathrm{~s}, 3 \mathrm{~s}, 4 \mathrm{~s}, 5 \mathrm{~s}, 6 \mathrm{~s}$ \\
\hline
\end{tabular}

Figure 9 shows the comparison between the VPP's request $\left(P_{V P P}^{\text {request }}\right)$ and VPP's reference $\left(P_{V P P}^{r e f}\right)$. As illustrated in Figure 9, the VPP's reference $P_{V P P}^{r e f}$ is generated without violating the system operating conditions of the SOC according to Equation (1). A positive VPP request is considered to be when the power flow is from the AC grid to the DC subgrid and the load. A negative VPP request is considered to be when the power flow is from the DC subgrid with the load to the AC grid.

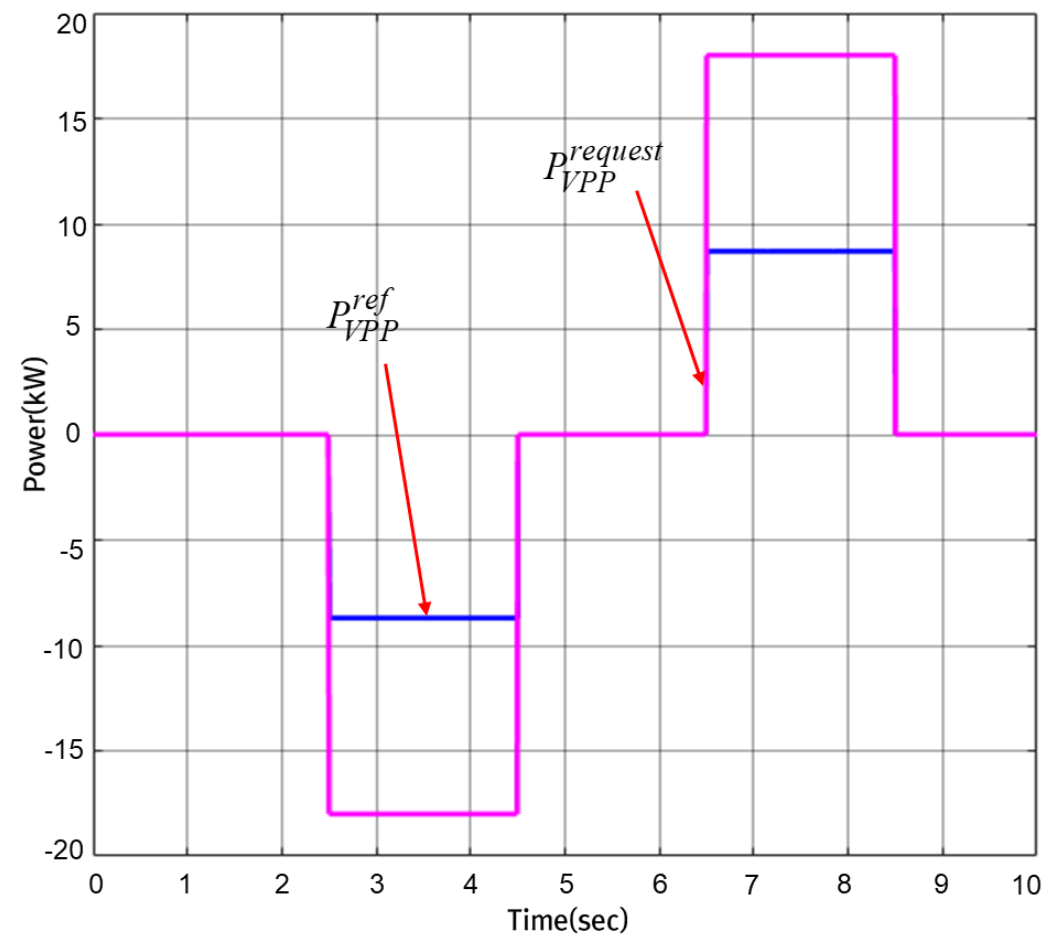

Figure 9. Comparison between the VPP's request and the VPP's reference.

Figures 10 and 11 show the voltage response and the power response, respectively. As shown in Figure 10, the voltage at each component output is well regulated within the required operating range, such as the AC voltage between $\left(0.94 \times V_{\text {rated }}\right) \leq V_{\text {rated }} \leq$ $\left(1.06 \times V_{\text {rated }}\right)$ and the DC voltage between $\left(0.9 \times V_{\text {rated }}\right) \leq V_{\text {rated }} \leq\left(1.1 \times V_{\text {rated }}\right)$. Figure 9 shows the performance of the power balance between the generation and consumption according to the variations in the loads and the VPP request power. In Figure 11, the DC subgrid performs well with the load variations. Moreover, the power trade, according to the VPP, is conducted sufficiently without violating the SOC condition-based criteria defined in Equation (1). 

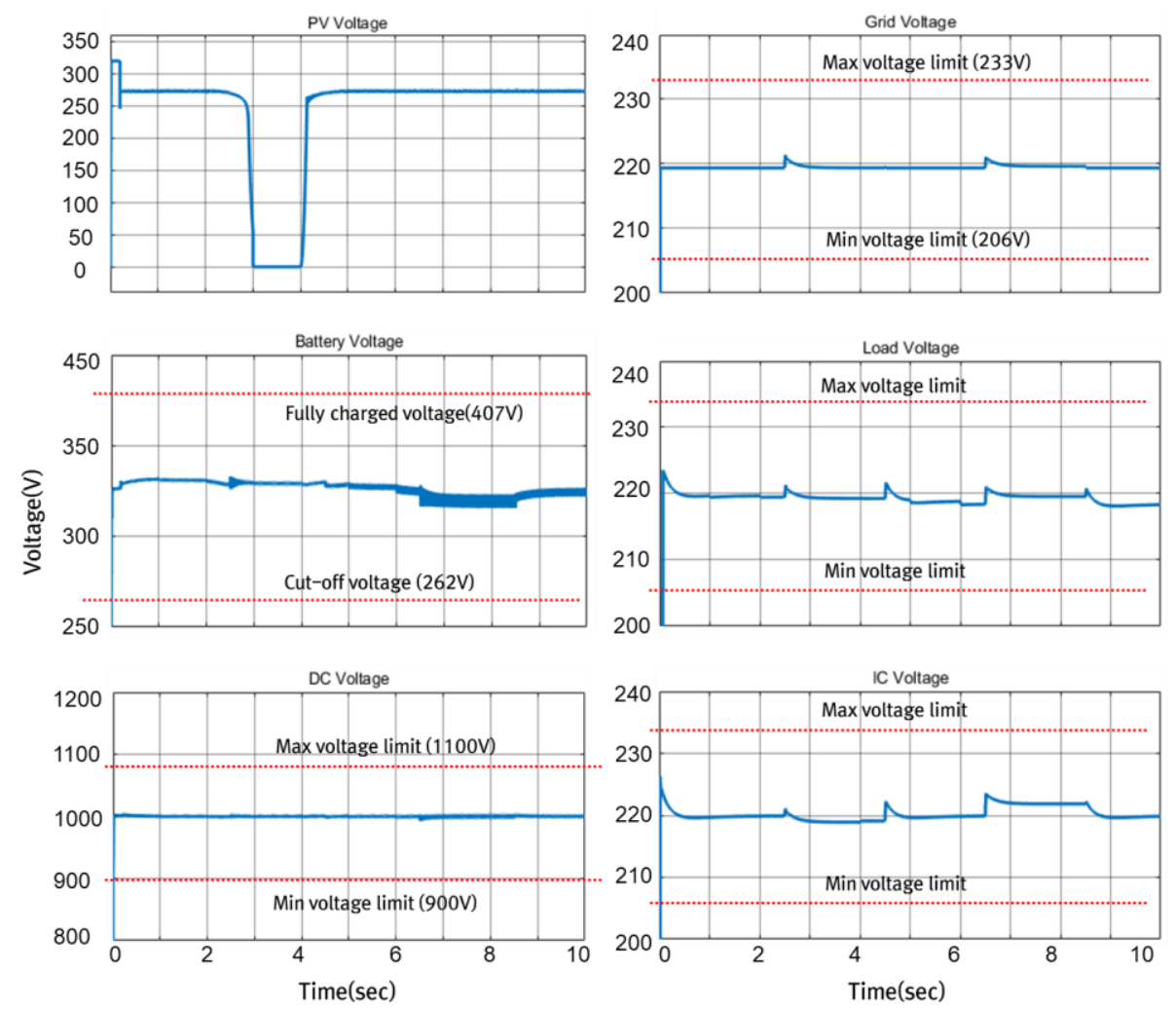

Figure 10. Comparison among voltages.
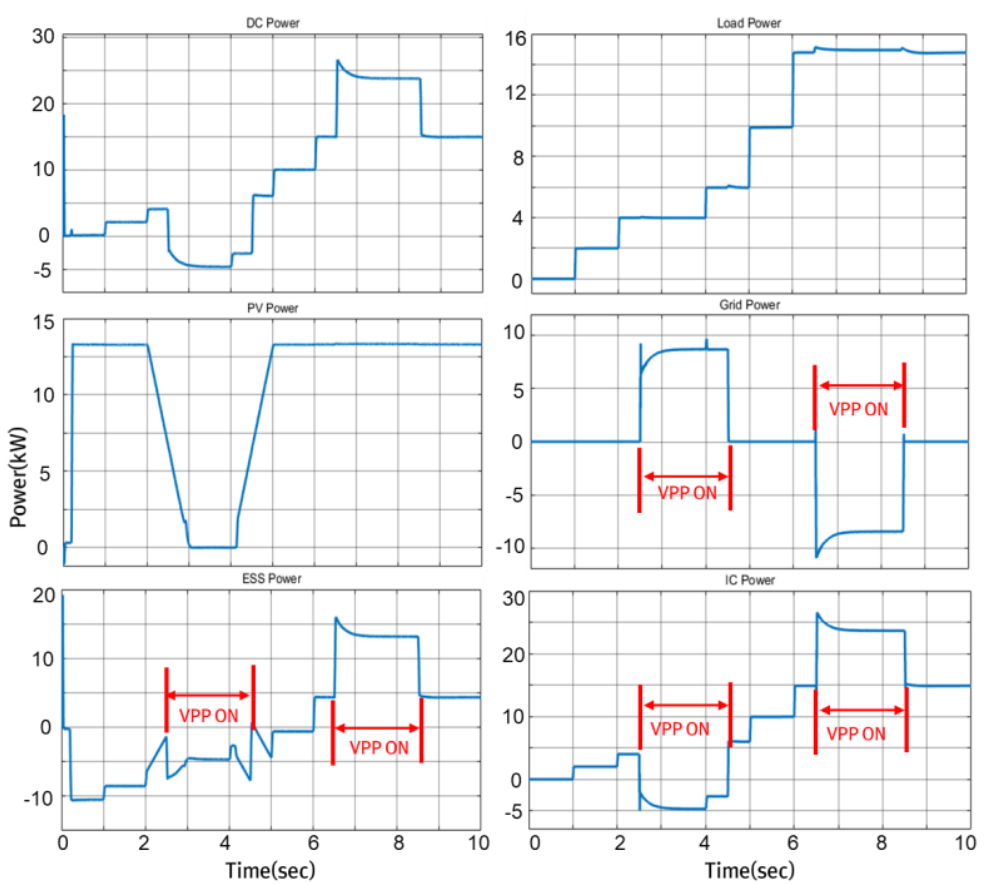

Figure 11. Comparison among powers.

\section{Discussion}

As depicted in the simulation studies, the supervisory power coordination performs well. When there is no VPP request, the power supply to the AC load is handled not by the grid, but by the DC subgrid (PV + ESS). When there is a VPP request, the ESS turns to the charging or discharging operation mode, while the PV generates its maximum power. The VPP's request is limited by the boundary conditions defined in Equation (1); thus, a 
proper VPP request is achieved without violating the system operating conditions. As a result, the proposed system architecture and the supervisory power coordination scheme are well justified.

\section{Conclusions}

This paper proposed a supervisory power coordination scheme. As demonstrated in the simulation, the supervisory power coordination scheme performed well in terms of the responses to the load and the VPP's request from the perspective of the power balance between the AC subgrid and the DC subgrid. In the proposed scheme, the pre-defined SOC parameters can be changed according to the system operating conditions. Furthermore, as depicted in the simulation studies, it is important to consider the system operating conditions, especially when a VPP request is required. Conclusively, the proposed system configuration and supervisory power coordination scheme demonstrate innovative performance in the prevention of excessive power penetration of REs into the grid, as well as contributing to VPP requests. The proposed scheme is readily applicable, reasonable, and justifiable in terms of its application in a variety of system configurations.

Author Contributions: Conceptualization, H.K. and G.K.; methodology, H.K.; software, G.K.; validation, G.K. and Y.N.; formal analysis, H.K.; investigation, G.K.; resources, Y.N. and K.R.; data curation, Y.N.; writing — original draft preparation, H.K.; writing—review and editing, H.K.; visualization, Y.N. and K.R.; supervision, H.K. All authors have read and agreed to the published version of the manuscript.

Funding: This research received no external funding.

Institutional Review Board Statement: Not applicable.

Informed Consent Statement: Not applicable.

Data Availability Statement: Not applicable.

Acknowledgments: This research was funded by the Ministry of Trade, Industry and Energy, and supported by the Korea Institute for Advancement of Technology (KIAT) (grant number P083700028). This work was also supported by a grant from the Korea Agency for Infrastructure Technology Advancement (KAIA), funded by the Ministry of Land, Infrastructure and Transport (grant number 21HSCTB157908-02).

Conflicts of Interest: The authors declare no conflict of interest.

\section{Appendix A}

Table A1. System Parameters.

\begin{tabular}{ll}
\hline ESSs & \\
\hline Nominal power & $15 \mathrm{kWh}$ \\
\hline Nominal discharging current & $18 \mathrm{~A}$ \\
\hline Cut-off voltage & $262 \mathrm{~V}$ \\
\hline Maximum SOC & $90 \%$ \\
\hline Fully charged battery voltage & $407 \mathrm{~V}$ \\
\hline Nominal voltage & $350 \mathrm{~V}$ \\
\hline Emergency maximum SOC & $95 \%$ \\
\hline
\end{tabular}


Table A1. Cont.

\begin{tabular}{|c|c|}
\hline \multicolumn{2}{|l|}{ PWM generator } \\
\hline \multicolumn{2}{|l|}{ (Boost and buck) } \\
\hline PI controller integral gain & 2 \\
\hline PI controller proportional gain & 50 \\
\hline \multicolumn{2}{|l|}{ (DC control) } \\
\hline PI controller proportional gain & 20 \\
\hline PI controller integral gain & 150 \\
\hline \multicolumn{2}{|l|}{ (Power control) } \\
\hline PI controller proportional gain & 0.5 \\
\hline PI controller integral gain & 5 \\
\hline PWM switching frequency & $20 \mathrm{kHz}$ \\
\hline \multicolumn{2}{|l|}{ AC/DC interlinking converter } \\
\hline Nominal power & $15 \mathrm{~kW}$ \\
\hline Nominal frequency & $60 \mathrm{~Hz}$ \\
\hline DC rated voltage & $1000 \mathrm{~V}$ \\
\hline \multicolumn{2}{|l|}{ (DC link controller) } \\
\hline DC voltage controller PI proportional gain & 2 \\
\hline DC voltage controller PI integral gain & 5 \\
\hline Current controller PI proportional gain & 10 \\
\hline Current controller PI integral gain & 50 \\
\hline \multicolumn{2}{|l|}{ (CVCF controller) } \\
\hline Voltage controller PI proportional gain & 5 \\
\hline Voltage controller PI integral gain & 10 \\
\hline Current controller PI proportional gain & 10 \\
\hline Current controller PI integral gain & 50 \\
\hline Inductance of LCL filter at the converter side & $300 \times 10^{-6} \mathrm{H}$ \\
\hline Inductance of LCL filter at the AC subgrid side & $10 \times 10^{-6} \mathrm{H}$ \\
\hline Capacitance of LCL filter & $110 \times 10^{-6} \mathrm{~F}$ \\
\hline Capacitance of DC link & $8800 \times 10^{-6} \mathrm{~F}$ \\
\hline PWM switching frequency & $20 \mathrm{kHz}$ \\
\hline \multicolumn{2}{|l|}{ DC/DC converter at the PV side } \\
\hline Capacitance at the DC subgrid side & $1500 \times 10^{-6} \mathrm{~F}$ \\
\hline Capacitance of LC filter & $500 \times 10^{-6} \mathrm{~F}$ \\
\hline Inductance of LC filter at the DC subgrid side & $0.2 \times 10^{-3} \mathrm{H}$ \\
\hline \multicolumn{2}{|l|}{ DC/DC converter at the battery side } \\
\hline Capacitance at the DC subgrid side & $500 \times 10^{-6} \mathrm{~F}$ \\
\hline Capacitance of LC filter & $300 \times 10^{-6} \mathrm{~F}$ \\
\hline Inductance of LC filter at the DC subgrid side & $0.2 \times 10^{-3} \mathrm{H}$ \\
\hline
\end{tabular}




\section{Appendix B}

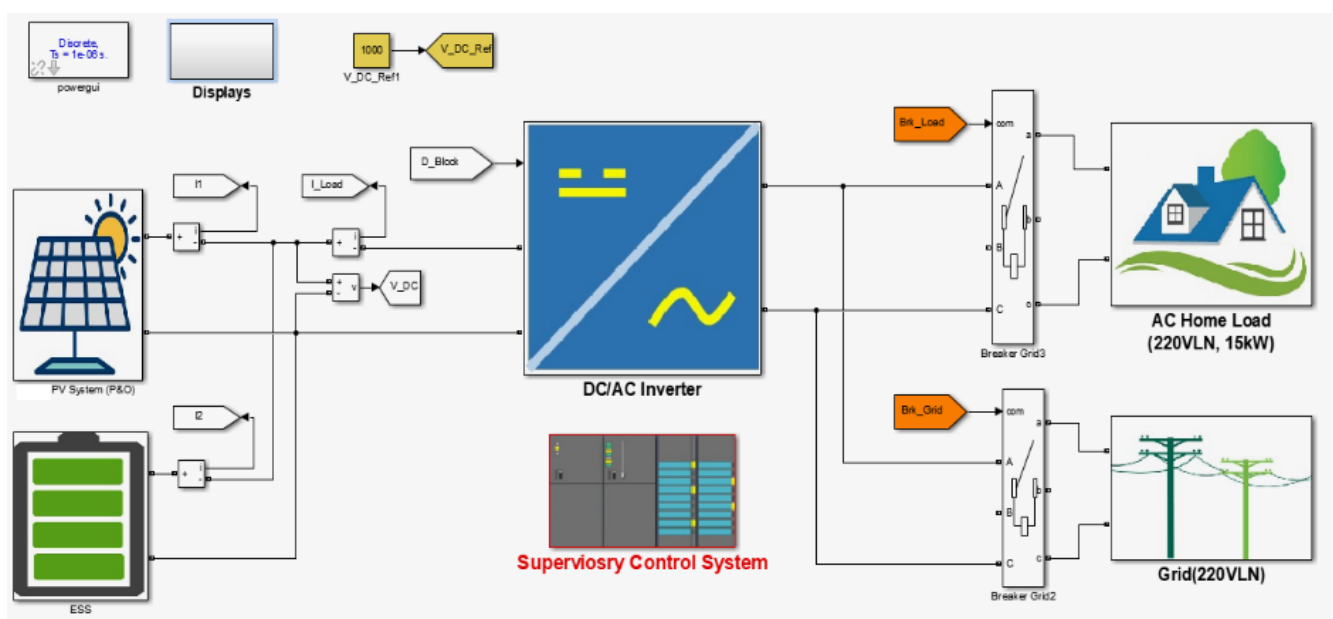

Figure A1. Dynamic modeling of the system configuration.

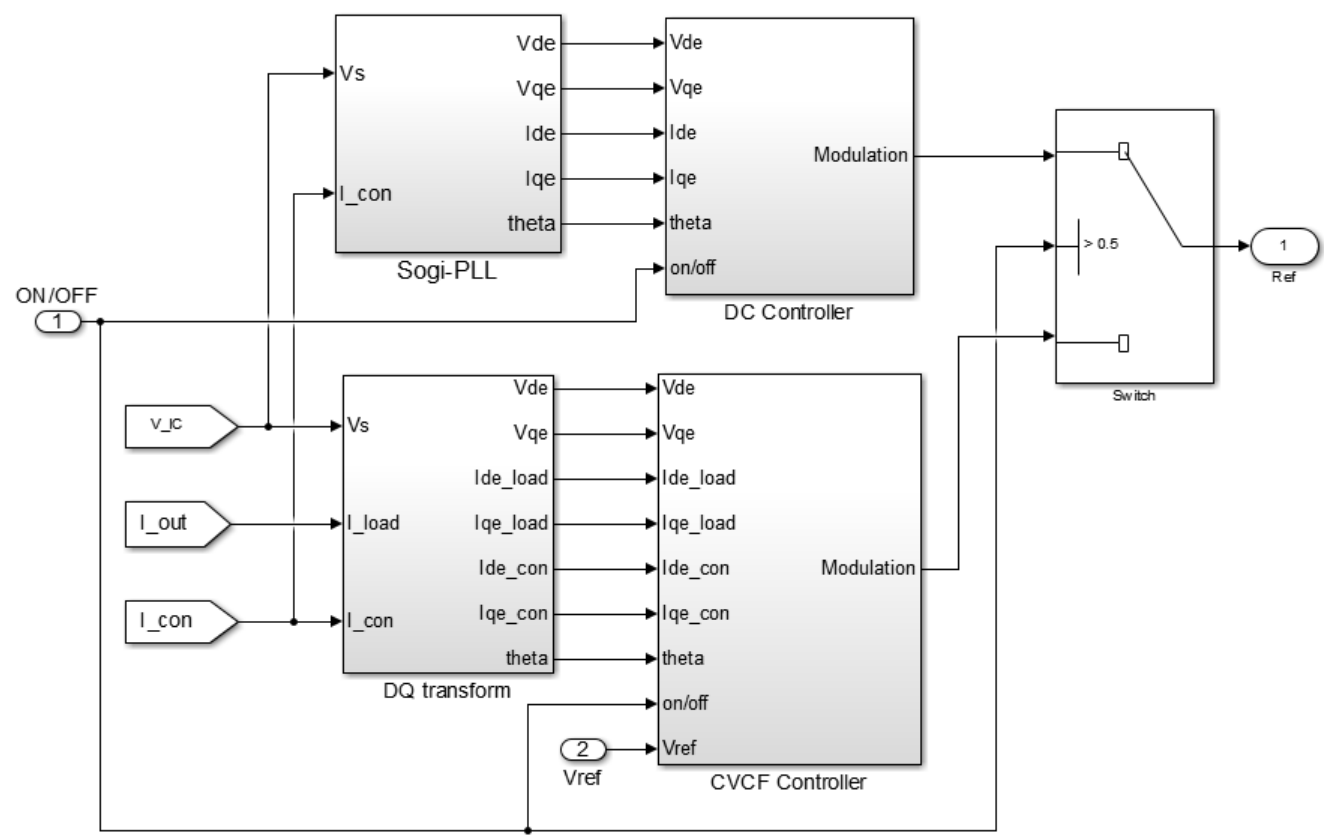

Figure A2. Control block diagram of the AC/DC interlinking converter.

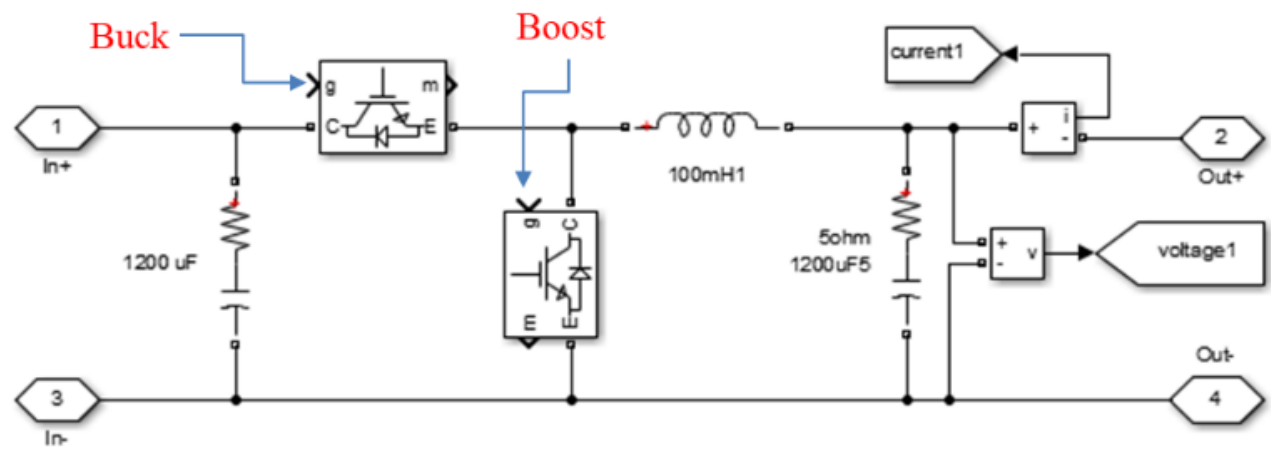

Figure A3. Bidirectional DC/DC converter. 


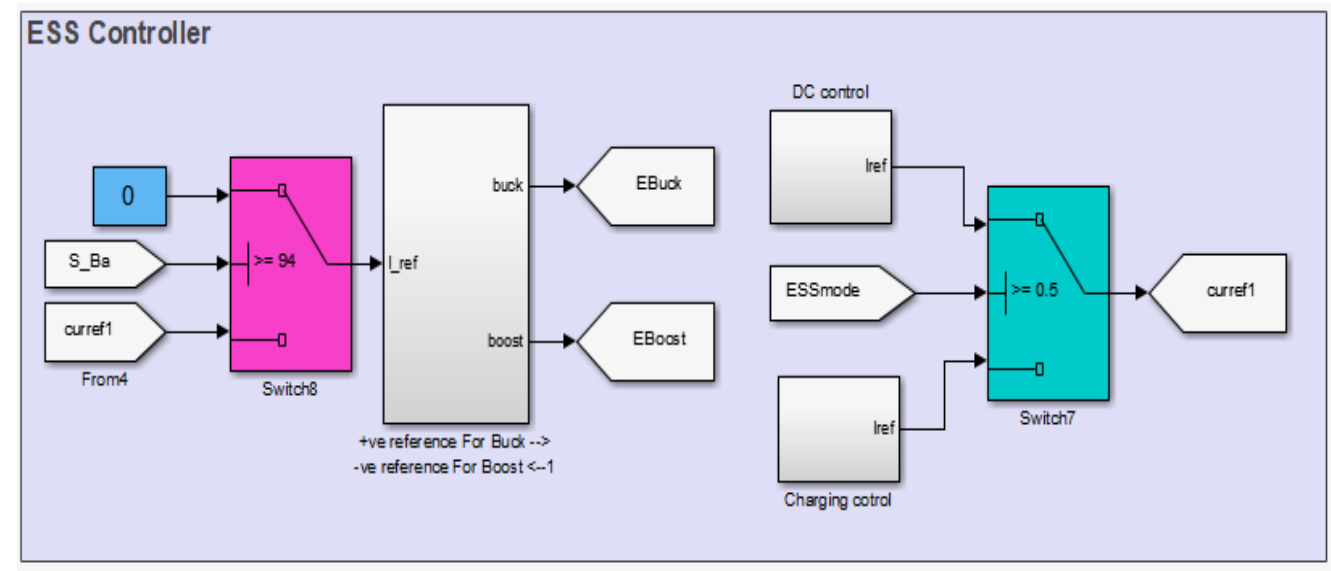

Figure A4. Control block diagram of the ESS.

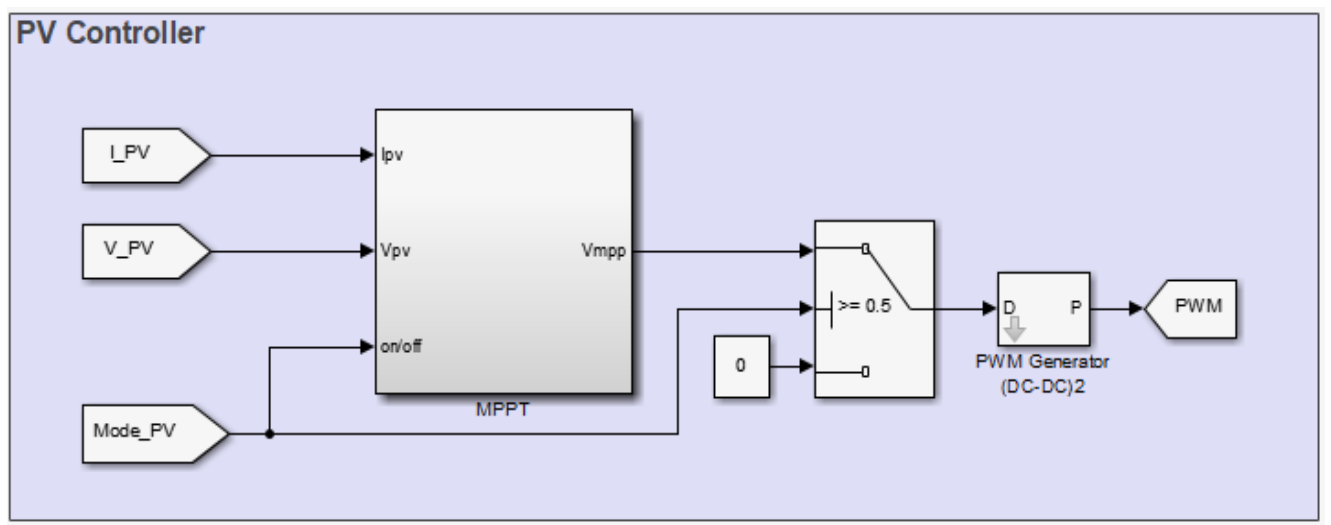

Figure A5. Control block diagram of the PV.

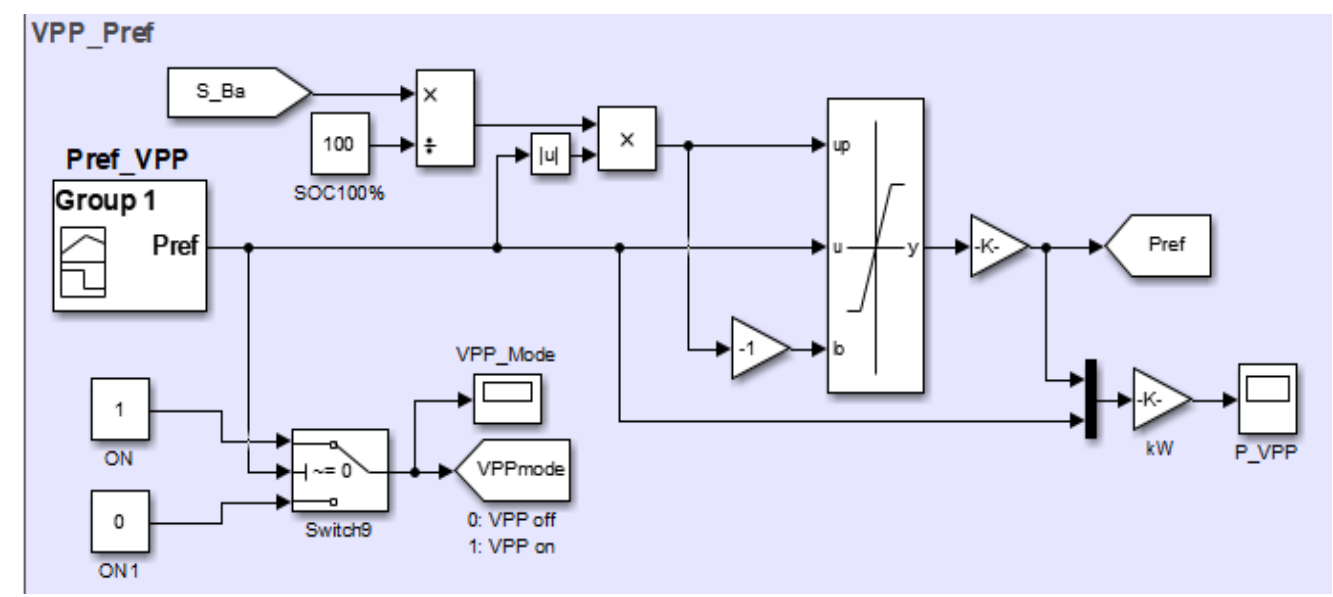

Figure A6. Block diagram of the VPP simulator. 

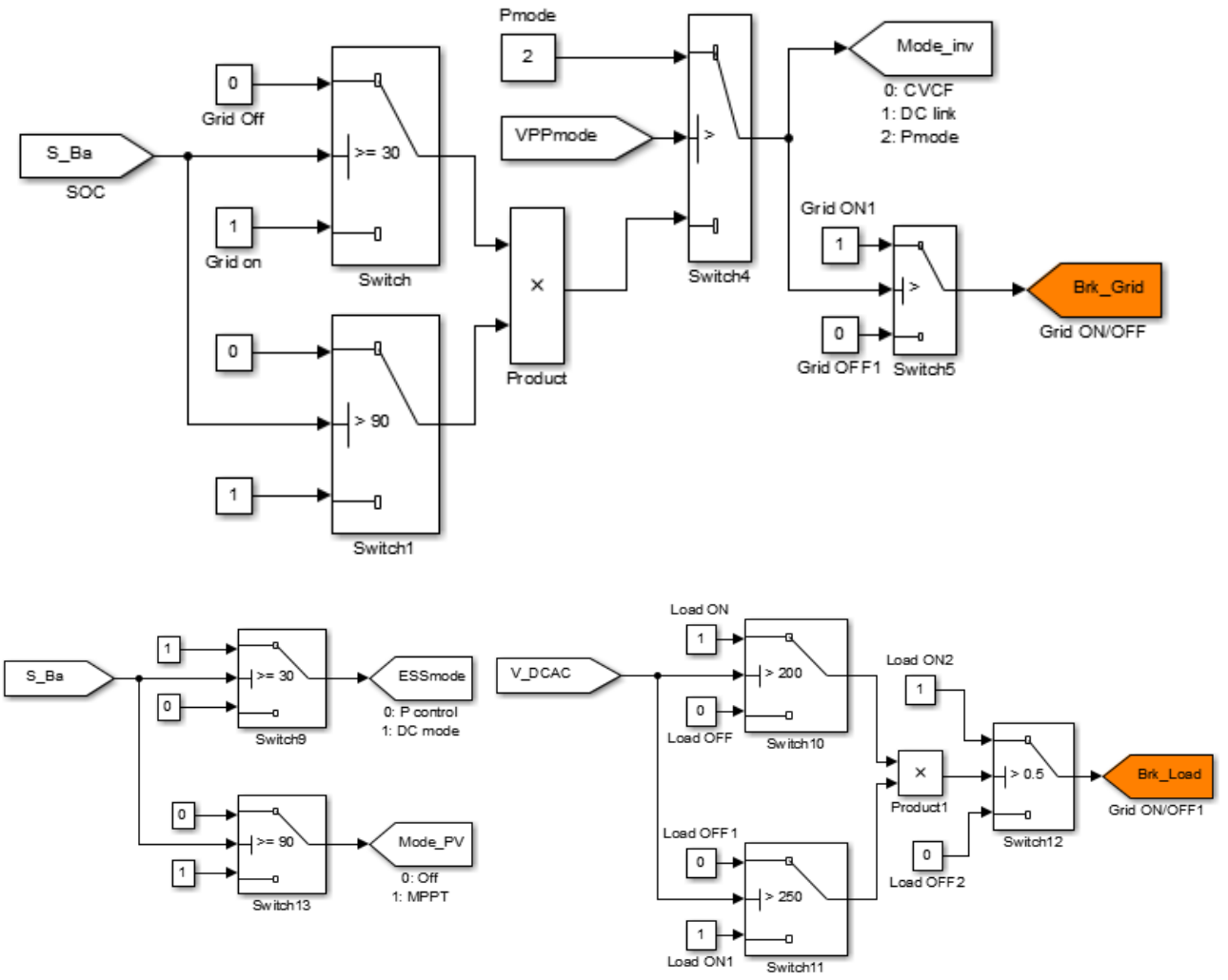

Figure A7. Concise block diagram of the supervisory power coordination.

\section{References}

1. Patterson, P.T. Dc, come home: Dc microgrids and the birth of the "enernet". IEEE Power Energy Mag. 2012, 10, 60-69. [CrossRef]

2. Zhang, L.; Liang, J.; Tang, W.; Li, G.; Cai, Y.; Sheng, W. Converting AC distribution lines to DC to increase transfer capacities and DG penetration. IEEE Trans. Smart Grid 2018, 10, 1477-1487. [CrossRef]

3. Wu, T.F.; Chang, C.H.; Lin, L.C.; Yu, G.R.; Chang, Y.R. DC-bus voltage control with a three-phase bidirectional inverter for DC distribution systems. IEEE Trans. Power Electron. 2013, 28, 1890-1899. [CrossRef]

4. Nguyen, T.T.; Yoo, H.J.; Kim, H.M. A comparison study of MVDC and MVAC for deployment of distributed wind generations. In Proceedings of the 2016 IEEE International Conference on Sustainable Energy Technologies (ICSET), Hanoi, Vietnam, 14-16 November 2016; pp. 138-141.

5. Wang, P.; Goel, L.; Liu, X.; Choo, F.H. Harmonizing AC and DC: A hybrid AC/DC future grid solution. IEEE Power Energy Mag. 2013, 11, 76-83. [CrossRef]

6. Guerrero, J.M.; Vasquez, J.C.; Matas, J.; De Vicuña, L.G.; Castilla, M. Hierarchical control of droop-controlled ac and dc microgridsła general approach toward standardization. IEEE Trans. Ind. Electron. 2011, 58, 158-172. [CrossRef]

7. Guerrero, J.M.; Chandorkar, M.; Lee, T.L.; Loh, P.C. Advanced control architectures for intelligent microgrids, part i: Decentralized and hierarchical control. IEEE Trans. Ind. Electron. 2013, 60, 1254-1262. [CrossRef]

8. Mahmood, H.; Michaelson, D.; Jiang, J. Accurate reactive power sharing in an islanded microgrid using adaptive virtual impedances. IEEE Trans. Power Electron. 2015, 30, 1605-1617. [CrossRef]

9. Bidram, A.; Davoudi, A.; Lewis, F.L. A multiobjective distributed control framework for islanded ac microgrids. IEEE Trans. Ind. Inform. 2014, 10, 1785-1798. [CrossRef]

10. Nasirian, A.; Shafiee, Q.; Guerrero, J.; Lewis, F.; Davoudi, A. Droopfree distributed control for ac microgrids. IEEE Trans. Power Electron. 2016, 31, 1600-1617. [CrossRef]

11. Guo, F.; Wen, C.; Mao, J.; Song, Y.D. Distributed secondary voltage and frequency restoration control of droop-controlled inverterbased microgrids. IEEE Trans. Ind. Electron. 2015, 62, 4355-4364. [CrossRef]

12. Bidram, A.; Davoudi, A.; Lewis, F.L.; Guerrero, J.M. Distributed cooperative secondary control of microgrids using feedback linearization. IEEE Trans. Power Syst. 2013, 28, 3462-3470. [CrossRef]

13. Sun, Q.; Han, R.; Zhang, H.; Zhou, J.; Guerrero, J. A multiagent-based consensus algorithm for distributed coordinated control of distributed generators in the energy internet. IEEE Trans. Smart Grid 2015, 6, 3006-3019. [CrossRef]

14. Schiffer, J.; Seel, T.; Raisch, J.; Sezi, T. Voltage stability and reactive power sharing in inverter-based microgrids with consensusbased distributed voltage control. IEEE Trans. Control Syst. Technol. 2016, 24, 96-109. [CrossRef]

15. Shafiee, Q.; Guerrero, J.M.; Vasquez, J.C. Distributed secondary control for islanded microgridsła novel approach. IEEE Trans. Power Electron. 2014, 29, 1018-1031. [CrossRef] 
16. Lu, L.Y.; Chu, C.C. Consensus-based droop control synthesis for multiple dics in isolated micro-grids. IEEE Trans. Power Syst. 2015, 30, 2243-2256. [CrossRef]

17. Simpson, J.W.; Orfler, M.P.; Bullo, F. Synchronization and power sharing for droop-controlled inverters in islanded microgrids. Automatica 2013, 49, 2603-2611. [CrossRef]

18. $\mathrm{Wu}, \mathrm{X}$.; Shen, C.; Iravani, R. Feasible range and optimal value of the virtual impedance for droop-based control of microgrids. IEEE Trans. Smart Grid 2016, 8, 1242-1251. [CrossRef]

19. Li, Y.W.; Kao, C.N. An accurate power control strategy for power-electronics-interfaced distributed generation units operating in a low-voltage multibus microgrid. IEEE Trans. Power Electron. 2009, 24, 2977-2988.

20. O'Shaughnessy, E.; Cruce, J.R.; Xu, K. Too much of a good thing? Global trends in the curtailment of solar PV. Sol. Energy 2020, 208, 1068-1077. [CrossRef] [PubMed]

21. Pollefliet, J. Power Electronics: Switches and Converters, 1st ed.; Academic Press: Cambridge, MA, USA, 2018.

22. Ko, H.S.; Jang, M.S.; Ryu, K.S.; Kim, D.J.; Kim, B.K. Supervisory Power Quality Control Scheme for a Grid-Off Microgrid. IEEE Trans. Sustain. Energy 2017, 9, 1003-1010. [CrossRef]

23. Perez, G.; Gandiaga, I.; Garmendia, M.; Reynaud, J.F.; Viscarret, U. Modelling of Li-ion batteries dynamics using impedance spectroscopy and pulse fitting: EVs application. World Electr. Veh. J. 2013, 6, 644-652. [CrossRef]

24. The Math-Works Inc. Matlab/Simulink Toolbox; The Math-Works Inc.: Natick, MA, USA, 2016. 